\title{
2006-909: TEAMING ACTIVITIES IN A FRESHMAN ENGINEERING AND COMPUTER SCIENCE COURSE AIMED TOWARDS RECRUITMENT AND RETENTION
}

\section{Blair Rowley, Wright State University}

BLAIR A. ROWLEY is a Professor of Biomedical, Industrial, and Human Factors Engineering and Director of the Freshman Engineering and Computer Science Program. He holds the Ph.D. from the University of Missouri, Columbia and is a PE. He has been in academia since 1970. Among his many activities he served as Chair of the ASEE/BMD 1987-1988 and is a reviewer for NSF. His research focus is on rehabilitation engineering and teaching.

\section{Kumar Yelamarthi, Wright State University}

KUMAR YELAMARTHI is a Ph.D. student and holds an MSEE from Wright State University. He serves as the lead Graduate Teaching Assistant for the Freshman Engineering and Computer Science Program. He was honored with the most outstanding graduate student in 2004 and excellent in teaching award for teaching assistants in 2005. He had authored three other papers. His research focus is VLSI design and Engineering Education.

\section{Thomas Bazzoli, Wright State University}

THOMAS L. BAZZOLI is Assistant Dean for Fiscal Affairs and Research. He holds the MS in Nuclear Science and Engineering from the Air Force Institute of Technology. During his Air Force career he directed diverse research programs in modeling and testing of system performance, compositional mapping of submicron materials and machine translation of text. He was instrumental in establishing the college's freshman program. 


\title{
Teaming Activities in a Freshman Engineering and Computer Science Course Aimed Towards Recruitment and Retention
}

\begin{abstract}
Our university has an open enrollment policy. This means that any person with a high school diploma can enroll in engineering or computer science. As a result entering students have a range of abilities from being excellent in math and science to struggling to understand algebra concepts. The current course, developed over the past five years has seen the overall engineering retention grow from $45 \%$ to $70 \%$. This has been accomplished through hands-on experience, establishing a sense of community, developing an understanding of how to be successful in studying, and fostering collaboration among students through cooperative teaming events. This paper describes three major teaming events within the freshman engineering and computer science course that have contributed to fostering collaboration and helped provide an enjoyable experience within the college.
\end{abstract}

Data from each event is provided which includes the students' candid feedback, what they like and dislike, and what implementations they would like to see in the future. Students discover that working as a team takes effort and that a team's result depends upon each member's efforts. Overall the teaming activities have been well received.

\section{Introduction}

The Freshman Engineering and Computer Science (FECS) Course at our university is designed to introduce engineering and computer science principles through hands-on experience, establish a sense of community, develop an understanding of how to be successful in studying engineering, and to foster collaboration among students through cooperative teaming. All incoming first year engineering students are required to take the FECS course. This course has one lecture section, a computer lab, and an instrumentation lab. The computer labs are designed for students to work independently and the instrumentation labs are designed for students to work in teams. A course outline is provided in Table 1.

The computer lab exercises involve e-mail and web searching, designing an airplane wing, HTML scripting, MatLab, Excel, and statistics, and how things work as the writing intensive assignment. The instrument labs cover 2-D and 3-D drawing using TurboCAD and SolidWorks, use of lab instruments, circuit measurements on resistive circuits, and building and testing a multivibrator, decade counter, and flip-flop using integrated circuits. In addition, basic soldering and basic wireless communication is taught using a temperature satellite. Apart from the labs, students also participate in three other teaming activities which are the focus of this paper. The three teaming events, three exams and two labs constitute $10 \%$ each, home work $15 \%$ and class participation $5 \%$ of the course grade.

During recruitment, students are introduced to FECS course and teaming events to show how engineering learning experience can be both fun and interesting. As a result, students, when entering FECS course, look forward to participate in the teaming events. These teaming events 
Table 1: Typical Outline of the FECS Course.

\begin{tabular}{|c|l|}
\hline Week & \multicolumn{1}{|c|}{ Focus } \\
\hline 1 & Bridge Building Competition \\
\hline 2 & Engineering Art, Email and Web - Plane Building Starts \\
\hline 3 & 3D Art and Fundamentals of Flight - Plane Building Done \\
\hline 4 & 3D Art and Web Design-I - Plane Flying Starts \\
\hline 5 & Exam I and Web Design-II \\
\hline 6 & Instrumentation and Web Design-III - Final Project Assigned \\
\hline 7 & Circuits and Engineering Math \\
\hline 9 & Timers, Flip Flops and other ICS, Exam-II \\
\hline 10 & $\begin{array}{l}\text { Temperature Satellite and How Things Work } \\
\text { Presentation of Final Project - Plane Flying Ends }\end{array}$ \\
\hline
\end{tabular}

involve building a bridge using K'NEX parts that is then tested to collapse, building and flying of an electrically powered radio controlled model airplane, and the design, construction and demonstration of an electro-mechanical device using the knowledge gained through the course.

The FECS course starts with an orientation session where students are introduced to the key people for the college and course such as the dean, assistant deans, professors and teaching assistants. During this orientation, students are asked how many of them know each other. It was found that only ten percent know any others. In order to increase the interaction among the students and aid them in transition from high-school to college, the course starts with a hands-on teaming event involving bridge building and testing.

\section{Bridge Project}

The course instructors searched for an initial teaming project where freshman students could experiment on their own, experience prototype frustrations and success, and have fun at the same time. Construction of a bridge using K'NEX parts and testing it for loading capacity was found to be a good project for this effort. Parts were readily available and inexpensive and could be assembled in multiple ways allowing for innovation during construction. Using the enrollment registration prior to the first class, students were randomly formed into teams of four. Team members were picked from the same lecture section. For the female students we tried to have at least two on a team. The teams were given four days to build prototypes and test them before the competition. As an aid, the course web site provided details and links to sites about bridges.

Each team was provided a kit of identical K'NEX parts and information about the parts inventory, qualification criteria, competition criteria, team log requirements, and grading. Prior to starting, each team inventoried the parts and any missing or bad parts were replaced.

\section{Qualification Criteria}

The bridge had to conform to the following to qualify for the test competition.

1. K'NEX parts were the only building materials that could be used.

2. Absolutely no modifications or additions to the K'NEX pieces were permitted.

3. All bridges had to be free standing and stable under no load conditions. 
4. All bridges had to have a span of at least forty inches. The span was defined as the distance between two opposite interior points of support. The areas defined by the support on either end of the span could be of any shape or size but had fit within one square foot.

5. The bridge had to provide a center clear span at least 12 inches wide by at least 6 inches deep.

6. All bridges had to include an area on the top surface of the span where the loading platform could be placed to permit incremental loading during the competition.

\section{Competition Criteria}

Any bridge that did not meet the qualification criteria was eliminated from the competition. During the competition, each bridge started with a loading platform placed at top center that weighed 7.5 pounds. Then weights were added to the platform in 1 to 10 pound increments until
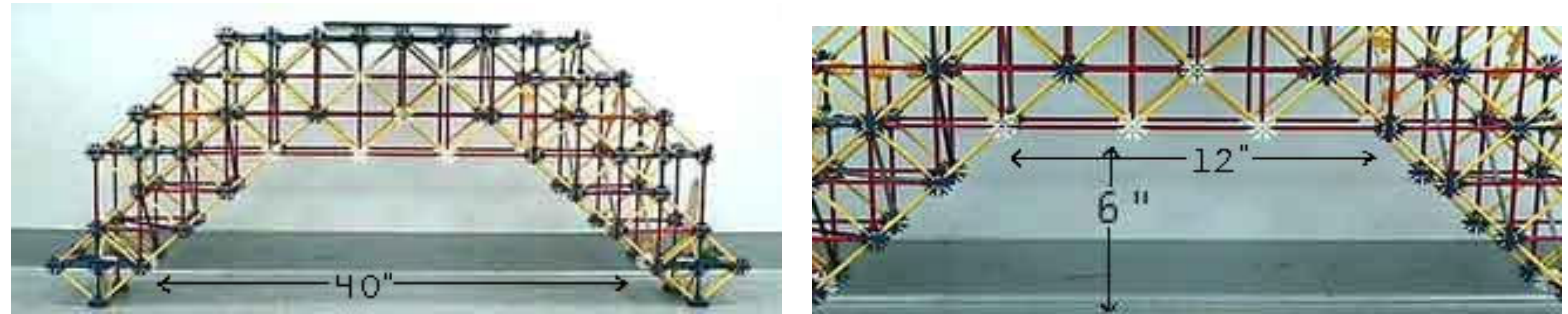

Figure 1: Minimum requirements for the support span, center span, and height and the location of the loading platform

the bridge broke. The last weight held before the bridge collapsed was recorded. The bridge that survived the heaviest load won and the team members were treated to dinner with the course professor. In case of a tie, the bridge with the largest "strength to weight" ratio was the winner. The maximum load divided by the weight of the bridge determined the "strength to weight".

\section{Team $\log$}

Each team was required to maintain a log of the week's events. This included when the team met, the time spent on the project, the different designs that were constructed, why a design failed, etc. The log had to be typewritten and contain entries for each of the days during which the bridge was being built and tested. A page was also required with pictures of the design attempts. The logs were signed by each team member and turned in during the bridge testing. An example log was provided on the course web site.

\section{Grading}

All students receive a "team" grade.

1. A qualifying bridge received 50 points.

2. A bridge that survived 51 to 69 pounds received 51 to 60 points

3. A bridge that survived a 70 to 80 pounds received 61 to 70 points

4. A bridge that survived a 90 to the max pounds received 71 to 80 points

5. The Team log was worth 1 to 10 points. 


\section{Results}

Building the bridge during the first week gave students time to meet others and learn to work together. Bridges were built, tested and rebuilt multiple times prior to the competition. Three to six times was common. During the week the instructor and course teaching assistants made it a

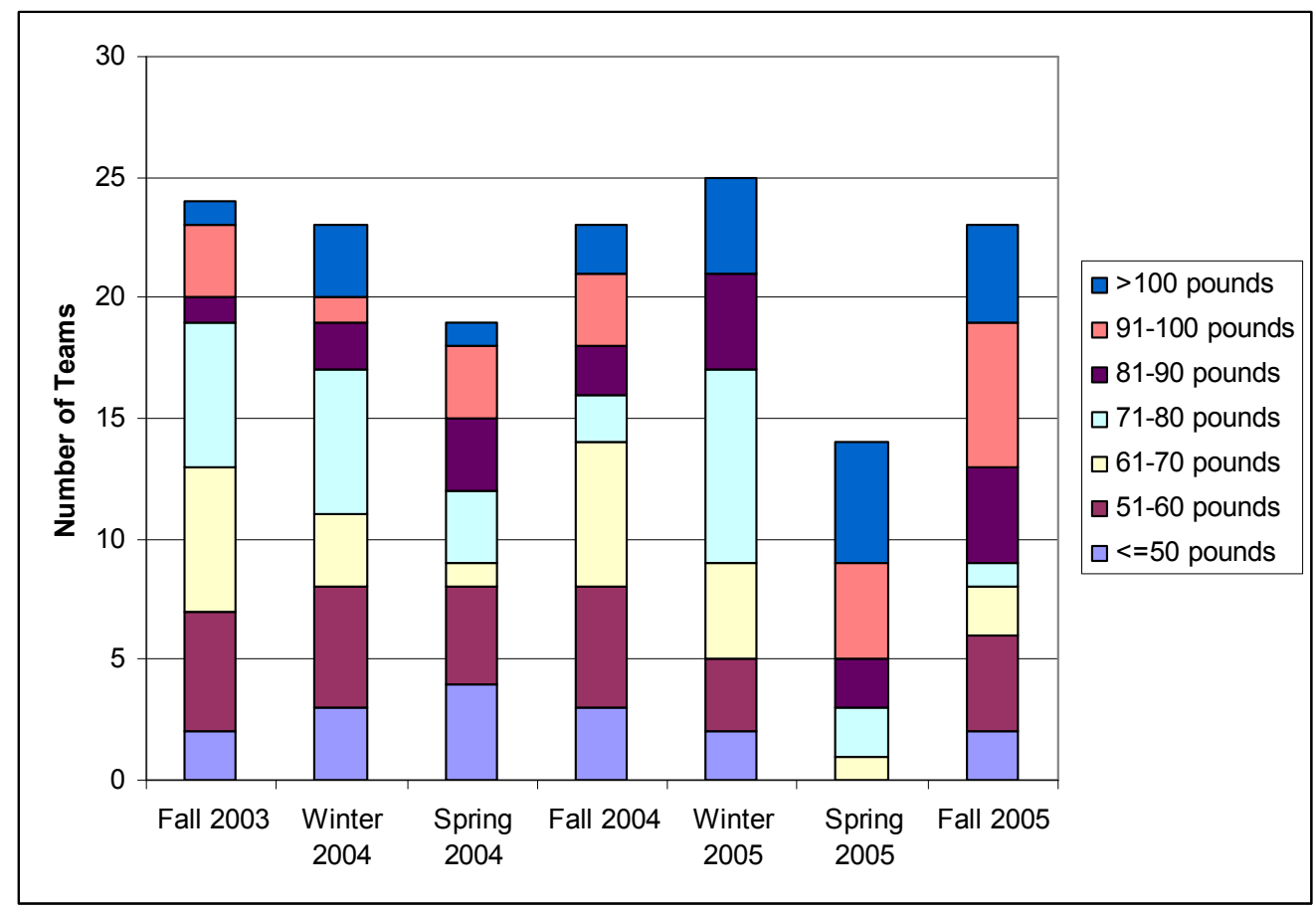

Figure 2: Results of Bridge Testing over Seven Quarters

point to encourage students and provide tips on how to design a better bridge. It was observed that the students received this very well. A weight testing station was provided 24 hours a day while the students were building their bridges. The teaching assistants were available periodically at the weight testing station to provide students with feedback on the bridges. Students who did not use the testing station used materials such as books and water bottle crates for weights. One interesting observation was that teams using the testing station were able to build a bridge that could withstand heavier loads.

On the day of competition, students registered their bridges and checked to see if they met the qualification criteria. Those that did not qualify were given the opportunity to make modifications. Before the competition, all of the teams gathered with their bridges for a group photograph. During testing, three stations were arranged with firm rubber mats and weights. A graduate teaching assistant was assigned to each station. The teams were called randomly to begin testing at one of the stations. During this time, there was cheering for the teams and lots of encouragement. Each team was photographed during bridge loading and all pictures taken were placed on the course web site. When a bridge failed, it did so catastrophically with lots of noise.

Figure 2 shows the trend of weights that bridges could sustain over the past seven quarters. The winning teams had bridges that supported from 111 pounds to 150 pounds before breaking. One team achieved 154 pounds but was disqualified when it was discovered that instant glue had 
been used on the stress points. It can be seen that there has been a trend towards increasing weight support each quarter. Fall 2003 with 24 teams had $20 \%$ achieve better than 80 pounds while in Spring 2005 with 14 teams it was 86\% and 60\% in Fall 2005 with 23 teams. In talking with the students it was obvious that the increase was due to the desire to do better than previous teams.

\section{Airplane Project}

This project was chosen because all students could participate, an appropriate airplane became available on the market, there was an excellent indoor facility available for flying, and experienced radio control flight instructors were available. Model airplane building and flying has been used as a student team event by others. Societies like the SAE have conducted student competitions where students compete with their planes against others to fly with the highest pay load. The University of Toledo has a project for seniors that involve flying a model plane on a computer, later building and flying the plane physically to compare the results of flight. However, none of the above projects involve freshman engineering students and the number of students involved was small. In the case of the SAE team from our university, it involved three students, one advisor, and a non student pilot. Recently it was reported in a local news paper that a professor in University of Dayton had introduced the concept of model plane building to freshman engineering students ${ }^{1}$. But no further information was forthcoming.

In the above cases, the time line for building and flying a plane ranged from 10 hours to months. Based on our course curriculum, it was decided that 4-5 hours per team could be allotted for this project. With this in mind, the criterion for this event was:

- Building and flying the plane should be completed in less than 5 hours.

- Every student on a team should be have time for flying the plane.

- The plane should be easily controllable by novice pilots.

- The plane should be slow flying and electrically powered.

- The team cost should be less than $\$ 50$.

- The experience should be educational and fun.

\section{Resources}

The resources required were: a place to fly, plane building supervisors, instructors to help the students learn to fly, and a budget for purchasing the plane's electronics. Because of weather concerns and the lack of daylight hours for flying during the week an indoor location was needed that could accommodate the slow flying airplanes. High school gyms, all weather tennis courts, and church multipurpose areas were considered. All had limitations of availability and size. Fortunately, our university has a large multipurpose arena, the Nutter Center, that its management was willing to make available for our students. Its size was ideal. It had a 70 foot plus ceiling and could accommodate over 10,000 spectators for basketball, hockey, and major concerts.

The course professor after much practice learned how to build the plane within two hours and then taught the course GTA's. The GTA's were then scheduled into two hour times slots over a 
two week period that student flight teams signed up for building. The course professor discovered rather quickly that learning to fly the plane was best done with an instructor-student set up. A local group of experienced radio control airplane instructors agreed to take on this task.

There were two expenses involved that are unique to this event, continuing compensation for the instructors and periodic upkeep on the plane's electronics after initial purchase (speed control, battery, receiver, servos, and transmitter). The plane was less then $\$ 40.00$, affordable by a student team and expendable. It came with a motor and propeller. The electronics however were considered too expensive for the students to purchase for just a few hours of use. In addition it was found that the electronics could be recovered and reused. So the college purchased them. They have been in use for five years with just a few replacements needed.

\section{Student Instruction}

Students received a lecture where they were taught the basics of flying. This involved forces, angle of attack, design of ailerons, elevators, rudder, wings etc. After the lecture, students had a lab session where they used a NASA's Airfoil simulator ${ }^{2}$ to determine the lift required for flying a plane and also to study the effect of different wing, ailerons, and rudder design parameters during flight. The students also formed teams of four, their choice, and were assigned build and flight times.

Table 2: Plane Event Survey Response

\begin{tabular}{|c|c|c|}
\hline \multirow{2}{*}{ Question } & \multicolumn{2}{|c|}{ Percentage } \\
\hline & Yes & No \\
\hline Do you have prior experience to flying RC planes? & 5.88 & 94.11 \\
\hline Did this project contribute to your learning experience? & 88.23 & 11.76 \\
\hline Did you have fun in this project? & 93.02 & 6.97 \\
\hline $\begin{array}{l}\text { Did this project Increase your interest in engineering } \\
\text { and computer science? }\end{array}$ & 84.70 & 15.29 \\
\hline \multirow[t]{2}{*}{$\begin{array}{l}\text { Did this project helped you develop your ability to work } \\
\text { as a team member }\end{array}$} & 83.33 & 16.66 \\
\hline & \multicolumn{2}{|c|}{$\begin{array}{l}\text { Overall Average } \\
\text { 1- Low, 5-Highest }\end{array}$} \\
\hline Rate the difficulty of this project in comparison with other work & \multicolumn{2}{|c|}{3.28} \\
\hline How well did all your team members work together as a team? & \multicolumn{2}{|c|}{4.55} \\
\hline
\end{tabular}

Student Plane Flying

Each flight team was allocated two hours to fly. When the students came to the arena, their plane was safety checked and made ready for flight. The students were then given individual instruction using the buddy box system and taught to fly. The buddy box system allowed the instructor to take over the plane when the student got it into trouble. The students learn to fly without help after ten minutes of instruction. This was remarkable as in the usual RC flight 
setting it takes hours. After all had flown, the team chose one member to participate as the pilot in a contest to see which team could make the most laps around the arena. Most made at least 30 laps.

\section{Grading}

The team grade was based upon having a plane ready to fly (40pts), being able to take off (25pts) and land (35pts), and the number of laps the pilot could make (10pts/lap).

At the end of the flight portion the students filled out a survey. The main results are presented in Table 2 .

\section{Results}

This event provided students with an educational and fun teaming experience. They learned basic principles of flight, experimented with wing design, and built and flew an airplane working in teams. A surprising outcome was how fast the students picked up on how to fly the RC airplane. Verbal feedback from students has been very positive and their enthusiasm for the event is high. At the end of the project, students were asked to fill out a survey. The main points of the survey showed that most had never flown a RC plane, that the project contributed to the students' learning experience, it increased their ability to work in teams, increased their interest in the colleges programs and they had fun in this project.

\section{Final Project}

The third teaming event was designed to test the students on the knowledge gained in the course. The objectives were to:

1. Use knowledge gained from this course for the project

2. Emphasize the concept of teaming

3. Improve presentation skills.

4. Improve team communication skills

5. Keep the cost incurred by each person to less than $\$ 20$

The project was based upon the concepts taught in four instrumentation lectures and labs. This involved basic resistive circuit measurements and analysis, design of simple circuits using batteries, switches, resistors, LED's and integrated devices such as the 555 timer, decade counters, flip-flops, and AND-gates. Most of this was done using breadboards. There was one lab devoted to learning how to solder a printed circuit.

At week six, students were introduced to the final project and were divided into teams of four of their choosing. This final project required students to construct and demonstrate an electromechanical device.

Two options for the final project were given:

1. Designing a device based upon a theme provided by the instructor. It had to have motion, at least six individual flashing light events, and play a tune. Motion meant that something had to move around. Individual light events meant that there were at least six lights going on and off in sequence. 
2. Design an environmental control unit for an individual with severe disabilities who can only use a single switch. The unit was to provide selection for and operate at least two battery operated items.

The grading for the project was meeting design requirements (50pts), creativity ( $25 \mathrm{pts})$, and presentation ( $25 \mathrm{pts})$. Each team was required to:

1. Provide a two minute power point presentation which ran automatically while students were setting their project.

2. Demonstrate their device.

3. Give a verbal presentation on their project.

The first 15 minutes of the presentation period was spent filling out a survey and some other administrative matters. Prior to the presentations, the teams' power point presentations were consolidated onto a CD. The order of presentation was randomized. As each team came forward to set up, their power point presentation was launched and ran automatically. Then the teams introduced themselves and demonstrated their project. The audience was asked to evaluate if they met the requirements and the professor kept notes. The whole process took 3.5 hours. While it was planned to hold the process down to 5 minutes per team, the positive interactions occurring with the audience caused slippage. Some of the projects were quite interesting in meeting requirements. Once, a singing fish "Billy Bass" was used with Christmas tree lights. As these simple solutions occurred, the requirements were tightened to require more originality. Majority of the projects used timers and decade counters as part of the design. Table 2 provides the results of the survey.

\section{Results}

Students responded well to this final project. Though there were few students who had worked on circuits while in high school, a majority of them did not. For this reason, the labs started with the basics of circuits such as current, voltage, resistance etc. Students when initially introduced to the project were worried thinking that they could not meet the requirements. As time went by, they felt comfortable as they were taught all the necessary concepts.

\section{Observations from Table 2}

1. Students considered several ideas before finalizing on their project.

2. A majority of students worked on the project using knowledge they gained from the course.

3. Students who had a leader in their team met more times to work on their project, had clear objectives for their project, distributed their work equally, and gave a better presentation.

4. A majority of students stated that the communication within their team increased while working together.

5. A few students sought outside help for the project. 
Table 2: Final Project Survey Responses

\begin{tabular}{|l|c|c|c|}
\hline \multicolumn{1}{|c|}{ Survey Items } & $\begin{array}{c}\text { Winter } \\
\mathbf{2 0 0 5}\end{array}$ & $\begin{array}{c}\text { Spring } \\
\mathbf{2 0 0 5}\end{array}$ & $\begin{array}{c}\text { Fall } \\
\mathbf{2 0 0 5}\end{array}$ \\
\hline $\begin{array}{l}\text { Number of different projects considered before finalizing on } \\
\text { the project }\end{array}$ & 2.7 & 2.7 & 3.4 \\
\hline Total Project Cost per person & $\$ 9.91$ & $\$ 9.04$ & $\$ 9.65$ \\
\hline Used experience gained from the EGR 190 labs & $85.71 \%$ & $85.79 \%$ & $85.67 \%$ \\
\hline Number of times team met & 5.46 & 3.56 & 6.02 \\
\hline There was a team leader for the group & $69.04 \%$ & $65.90 \%$ & $100 \%$ \\
\hline Work was distributed evenly & $88.09 \%$ & $97.72 \%$ & $70.51 \%$ \\
\hline Sought outside help during the project & $42.85 \%$ & $50 \%$ & $95.87 \%$ \\
\hline Time Spent on Power Point Presentation & $2 \mathrm{hours}$ & $1 \mathrm{hr} 30 \mathrm{~min}$ & $1 \mathrm{hr} \mathrm{30} \mathrm{min}$ \\
\hline Time Spent on Verbal Presentation & $40 \mathrm{~min}$ & $30 \mathrm{~min}$ & $30 \mathrm{~min}$ \\
\hline Personal contribution to the team & $78.87 \%$ & $76.86 \%$ & $78.77 \%$ \\
\hline There was better communication in the team as time went by & $\mathrm{n} / \mathrm{a}$ & $95.45 \%$ & $94.8 \%$ \\
\hline Team has grown as time went on while working together & $\mathrm{n} / \mathrm{a}$ & $90.9 \%$ & $89.87 \%$ \\
\hline Everyone accepted their responsibilities & $\mathrm{n} / \mathrm{a}$ & 95.45 & 88.6 \\
\hline Everyone attended all the meetings & $\mathrm{n} / \mathrm{a}$ & 79.54 & 64.47 \\
\hline
\end{tabular}

\section{Conclusion}

The three teaming events provide students basic understanding and training on engineering principles, teaming, communication skills, and leader ship qualities. Although each project varied in the requirements, all of them focused on teaming. The bridge building project helped students meet one another and start keeping an engineering log. The airplane project taught principles of flight and tied it together by team building a plane and learning to fly. This helped increase their interest in engineering and computer science, further developed their teaming, and was a good learning experience. The final project helped students understand how to apply what they learned in lecture and lab, increased their teaming, and contributed to their communication skills. These events have evolved over the last five years to become tools for recruiting and contributing to the increase in overall engineering student retention from $45 \%$ to $70 \%$.

\section{References:}

[1] M. Camm, "Backpack airplane being developed by UD engineers," Dayton Daily News (March 25, 2004), sec. Neighbours, pp.11.

[2] NASA Airfoil Simulator, Internet: http://www.grc.nasa.gov/WWW/K-12/airplane/foil2.html. 